\title{
METHODOLOGY FOR EVALUATING THE EFFECTIVENESS OF MACHINE AND EQUIPMENT MAINTENANCE SYSTEMS
}

\author{
Valery Vladimirovich Glushchenko *1凶 iD \\ ${ }^{* 1}$ Moscow Polytechnic University (Mospolitech), Professor of the Center for Project Activities, \\ Doctor of Technical Sciences, Associate Professor, Moscow
}

DOI: https://doi.org/10.29121/IJOEST.v5.i2.2021.166

Article Type: Research Article

Article Citation: Valery

Vladimirovich Glushchenko. (2021).

METHODOLOGY FOR EVALUATING

THE EFFECTIVENESS OF MACHINE

AND EQUIPMENT MAINTENANCE

SYSTEMS. International Journal of

Engineering Science Technologies,

5(2), 58-68.

https://doi.org/10.29121/IJOEST.v

5.i2.2021.166

Received Date: 02 March 2021

Accepted Date: 03 April 2021

Keywords:

System

Machine

Evaluation

Efficiency

Equipment

Methodology

Technical Service

Service

Consumer

Model

\section{ABSTRACT}

The subject of the article is the methodology for evaluating the effectiveness of technical service systems of machines and equipment, the object of the article is the system of technical service of machines, the purpose of the article is to develop a methodology for evaluating the effectiveness of technical service systems of machines; to achieve this goal, the tasks are solved: the concept of the methodology for evaluating the effectiveness of the system of technical service of machines and equipment is clarified; the methodology of the system approach is formed when evaluating the effectiveness of complexes of technical service of machines and equipment; the methodology of modeling the system of machine technical service services is being developed; a set of indicators for evaluating the effectiveness of machine technical service systems is being formed; in the article, the research methods are typical representations of machines, expert assessments, analysis and synthesis, a system approach, comparative and logical analysis, and heuristic modeling; the scientific novelty of the article is determined by the development of methodological provisions for evaluating the effectiveness of technical service of machines, the synthesis of a set of standard representations (models) of technical service systems of machines, the formation of criteria for evaluating the effectiveness of a technical service system.

\section{INTRODUCTION}

The relevance of the article is determined by the fact that to ensure the competitiveness of mechanical engineering products (machinery and equipment), it is necessary to create an effective system of technical service. Technical service is aimed at ensuring the safety of operation and operability of mechanical engineering products.

The purpose of the article is to develop a methodology for evaluating the effectiveness of technical service systems for machines and equipment.

To achieve this goal, the following tasks are solved:

- the concept of methodology for evaluating the effectiveness of the system of technical service of machinery and equipment is clarified;

(c) 2021 The Author(s). This is an open access article distributed under the terms of the Creative Commons Attribution License, which permits unrestricted use, distribution, and reproduction in any medium, provided the original author and source are credited. 
- a methodology of a systematic approach is being developed for evaluating the effectiveness of complex technical services for machinery and equipment;

- the methodology of modeling the system of machine maintenance services is being developed;

- a set of indicators is formed to evaluate the effectiveness of machine maintenance systems.

The object of the article is the system of technical service of machines.

The subject of the article is the methodology for evaluating the effectiveness of technical service systems for machines and equipment.

All types of mechanical engineering products (machinery and equipment) go through the following stages of their life cycle: design, production, market circulation, customer operation, and disposal.

The cost of owning machines and equipment at the stage of their operation is 80-90\% of all the costs of owning such objects. Most of these costs are the costs of technical maintenance of machinery and equipment.

This makes the task of improving the efficiency of technical service of machines relevant. Therefore, scientists develop a systematic approach in the technical service of mechanical engineering products [[1], p. 55-58].

Part of the technical service is its information and technical support [[2], p. 216]. To improve the efficiency of technical service systems, work quality management methods are used [[3], p. 31-39].

The effectiveness of technical service systems is increased by evaluating the level of technologies of such a service [[4], p. 36-39].

Methods of analysis of technical service systems of machine-building products are developed [[5], p. 83-104]. When designing and analyzing technical service systems, you can use standard representations of such technical service systems [[6], p. 36-43]. Mathematical modeling of machine maintenance systems is used to improve the efficiency of such a service [[7], p. 18-23]. Multi-factor experiments help to find the best options for machine maintenance systems [[8], p. 30-41].

In the course of research, a technical service system can be presented as a complex system. Such a system is characterized by a large number of internal connections between the elements [[9], p. 3-12].

Improving the efficiency of technical service systems can be achieved as a result of the analysis of management activities in such technical service systems [[10], p. 170-195].

A technical service system can be represented at the level of the functions it implements. With this approach, you can use a functional-decomposition representation of machine maintenance systems [[11], p. 184-186].

At the same time, the process of forming scientific and methodological support for the sphere of technical service of agricultural machinery and equipment proceeds within a certain paradigm. This paradigm reflects the level of development of the science of technical service [[12], pp. 228-243]. At the same time, modeling of technical service services is actively used [[13], p.2-5]. A four-level model of machine and equipment maintenance service can be developed [14].

The technical service infrastructure is becoming more complex. Therefore, a systematic approach is being developed in the design and analysis of such an infrastructure [[15], p. 107-113]. To improve the efficiency of technical service systems, an analysis of the use of various types of resources is carried out [[16], p.157-168]. However, the methodology for evaluating the effectiveness of technical service systems for machinery and equipment has not yet been formed. This confirms the relevance of this article.

\section{METHOD}

The system of technical service of machines and equipment will be considered a certain list of logically related types of technical service operations. This is a set of services provided to the owner of machinery and equipment (customer) by technical service organizations. Technical service services are required depending on: the occurrence of machine failures; certain facts during the operation of the machines. Such facts can be: the period of operation time (for example, 1 year); the volume of products produced on this machine. Machine maintenance services are provided in the order specified by the machine manufacturer (or simultaneously). Such a set of services is provided in accordance with the agreed schedule. This set of services is designed to ensure the achievement of a given technical goal. The goals of the technical service can be: ensuring the safety of the machine; restoring the machine's operability; preventing machine failures, and so on. The objectives of the technical service will be determined by the need to ensure the economic efficiency of the operation of machinery and equipment. 
Another definition of the system of technical service of machines and equipment is also possible. The system of technical service of machines can be called a set of elements (machines, equipment, buildings, etc.) that ensure the performance of service operations. These service operations should be described in special technical regulations. One of the purposes of such maintenance operations may be to extend the designated service life of machines and equipment during their operation.

The system of technical service of machines can be studied from an organizational and institutional point of view [[17], p. 162-165]. In the organizational aspect, the system of technical service of machines can be described as an association of organizations (or their departments). Each of these organizations provides a specific set of technical services.

In the institutional approach, the sphere of machine service is considered as a system of specific industrial, social and economic relations [[17], p. 162-165].

The effectiveness of machine maintenance systems is the ability of such systems to achieve their goals. In this case, the goal must be achieved in compliance with the following restrictions: the goal is achieved within a specified period of time; the goal is achieved when using resources in the amount not exceeding a certain value.

The assessment of the effectiveness of the technical service systems of machines will be called the assignment by an expert of a certain value to the indicator of the effectiveness of the technical service system. Such assignment of a certain value of an efficiency indicator is made on the basis of: execution of calculation and analytical procedures by the expert; expression of expert opinion in the course of the survey, filling out the questionnaire.

An indicator of the effectiveness of a technical service system is one of the most important indicators of this system. Such important indicators characterize the system of technical service to its users (subjects). As users of the technical service system, the following can be considered: owners of machinery and equipment (individuals or legal entities); technical service organizations that provide their services; state, regional, and municipal government bodies; state statistics bodies, and others.

The need for a systematic approach to evaluating the effectiveness of machine maintenance systems is related to the complexity of such systems. The system of technical service of machines is characterized by all the properties of complex systems: a large number of elements; physical heterogeneity of elements; emergence, expressed in the irreducibility of the properties of the whole to the properties of individual elements; hierarchy; reliability; flexibility and others [[18], c. 67]. A systematic approach to evaluating the effectiveness of machine maintenance systems is expressed in the study of all the performance indicators of such a service in their system unity and mutual connection.

The evaluation of the performance indicator of the technical service systems of machines is the result of the analysis of the technical service system under study. Methods of analysis in management activities were studied in the article [[10], p. 170-195]. The analysis of the systems of technical service of machines will be called the process of determining the cause-and-effect relationships between: on the one hand-the content of the operations of technical service of machines; on the other hand-the indicators that characterize the economic efficiency of these operations of technical service.

The analysis of the technical service systems of machines is related to: the decomposition (division) of this system into its parts (decomposition); the study of individual parts of the technical service system; the study of the nature of the relationships between the parts of the service system. In this analysis, functional decomposition and other types of representations of technical service systems can be used [[6], p. 36-43; 11, p. 184].

A systematic approach to assessing the effectiveness of machine maintenance systems should be formed within a certain paradigm [[12], p. 228-243]. An important element of this paradigm is the philosophy of a systematic approach to evaluating the effectiveness of machine maintenance systems.

Under the philosophy of a systematic approach to evaluating the effectiveness of machine maintenance systems, we will understand the wisest, most general view of the essence, content and meaning of such an assessment. Such a philosophy should be a philosophy of a systematic approach to ensuring the competitiveness of machines of certain manufacturers-machine-building enterprises. The philosophy of evaluating the effectiveness of machine maintenance systems forms the principles of analyzing and evaluating the effectiveness of machine maintenance systems. These principles are of great practical importance. The principle of analysis and evaluation of the effectiveness of technical service systems can be called the most general fundamental provisions of such analysis [[5], p. 83-104]. 
The following key provisions are proposed to be considered as the principles of the system approach in assessing the effectiveness of technical service systems:

- The principle of statehood requires that the objectives of such an assessment of effectiveness should not contradict the interests of the state;

- The principle of scientific character states that the existence of system connections between different parts of the technical service system should be justified at the current level of science;

- The principle of complexity emphasizes that the system assessment should cover all aspects of the functioning of technical service systems that are essential for consumers;

- The principle of mutual influence accounting requires: taking into account the relationships of indicators (parties of technical service) in the course of such an assessment of the effectiveness of technical service systems; taking into account the relationship of indicators in the interpretation of the results of such an assessment of the effectiveness of service systems;

- The principle of objectivity means the requirement to minimize the subjective component in the assessments and conclusions on the effectiveness of technical service systems;

- The principle of effectiveness of system performance assessments implies the existence of the possibility of developing and implementing measures aimed at improving the received performance assessment;

- The principle of planning states that it is necessary to make plans: a plan for implementing a system performance assessment; a plan for using such assessments in the interests of improving the efficiency of the machine maintenance system;

- The principle of timeliness is designed to ensure that the results of the assessment under consideration can be applied to improve the efficiency of technical services by managing the processes of such services in real time (quickly enough);

- The principle of reliability of efficiency estimates means a reliable reflection of the real level of efficiency of the analyzed machine maintenance systems;

- The principle of democracy asserts the possibility of discussing the results of such an assessment of the effectiveness of machine maintenance systems between the stakeholders of this process;

- The principle of efficiency requires a return on the cost of conducting such systematic performance assessments.

- Compliance with these principles of a systematic approach when evaluating the effectiveness of machine maintenance systems reduces the likelihood of errors. Such errors may occur when forming a methodology for evaluating performance. Errors can also be made when evaluating the effectiveness of agricultural machinery maintenance systems.

- In the practical implementation of the system approach, the following procedures play an important role in evaluating the effectiveness of machine maintenance systems:

- Decomposition of the whole into parts - decomposition of the machine maintenance system;

- System integration (aggregation) of elements and indicators describing them into characteristics of a higher level of the hierarchy;

- Detailing the decomposition of estimates of summary performance indicators of technical service systems by various attributes (for example, using a graph-tree of performance indicators);

- Comparison of estimates of indicators, which is the process of identifying differences and similarities of the studied indicators, taking into account: the possibility of comparing the estimated parameters, the uniformity of indicators, the similarity of the methodology for their assessment;

- Grouping of estimates, which covers the distribution of the estimated indicators (phenomena) into groups, subgroups, and more.

In a systematic approach to evaluating the effectiveness of machine maintenance systems, the object of such an assessment is not only the result,but also the entire process of the entire service system. Therefore, an assessment can be carried out: the reliability of indicators; the effectiveness of processes in the system of technical service of machines; the practical results of the performed assessment of the effectiveness of technical service systems.

There is an increase in the role and complexity of machine maintenance systems. Therefore, there is a growing need for multivariate analysis and evaluation of the effectiveness of such systems. A multivariate evaluation of a technical service system consists in the fact that the same technical service system (the object of evaluation) is 
analyzed using different methods. In multivariate analysis and performance evaluation, the results of the evaluation that are verified (confirmed) using other methods are considered reliable.

At the design stage of machines, a predictive assessment of the effectiveness of technical service systems can be useful.

The forecast assessment of the effectiveness of technical service systems is formed on the basis of the results of the forecast analysis. At the same time, the future state of the technical service system (tehservice) is subjected to a predictive analysis. This future state of the technical service system is created by making specific strategic technical, technological and managerial decisions.

At the design stage, predictive evaluation and analysis of the effectiveness of technical service systems do not exist separately. They are in system unity with the process of synthesis of both the machines themselves and the synthesis of their technical service systems. This is due to the fact that the location of the machine components, the features of its design, the choice of structural materials for machines serve as the initial data for the design of machine maintenance systems. The design features of machines affect the technical and technological features of their technical service systems.

It is recommended to take into account that already in the course of designing machines, models of their technical service are offered. Conclusions based on the results of assessments of the effectiveness of machine service systems can be used in the following tasks: identifying problems in the functioning of technical service systems; collecting and processing information at the stage of machine operation; analyzing information about machine failures during their operation; diagnosing the causes of low efficiency of the technical service system; generating proposals for improving the efficiency of technical service systems; when predicting the results of the implementation of the proposed measures; when preparing technical, technological and management decisions in the technical service system; when familiarizing with the management decisions of performers and managers; when organizing the implementation of decisions made; when evaluating and monitoring the level of efficiency of the machine maintenance system.

Such classification of the considered assessments of the effectiveness of technical service systems is possible:

- on the basis of the hierarchical level, it is possible to distinguish assessments of the effectiveness of technical service systems at the levels of: national economy (macroeconomic); assessments at the level of organizations (microeconomic); assessments that combine macroeconomic microeconomic assessment levels (mesoeconomic);

- express assessments that are carried out in a short time to ensure control of the effectiveness of management in real time of the functioning of the technical service system [ [18], c. 266];

- in-depth assessments of the effectiveness of the technical service system at several levels of the hierarchy (state, industry, organization);

- multivariate assessments of the effectiveness of technical service systems based on several different research methods (experimental, analytical, expert and other methods);

- based on the factor of the breadth of coverage of the technical service system, it is possible to distinguish complex and thematic assessments of the effectiveness of technical service systems;

- according to the disposition of the evaluation time relative to the time of the actual technical service process, the following types of assessments can be distinguished: previous (planned) assessments received before the start of the technical service process; real-time performance assessments of the technical service; subsequent assessments after the completion of the technical service process of the machine;

- according to the period of remoteness of the time of occurrence of consequences, it is possible to distinguish: operational assessments (used in the analysis of the real situation within one calendar month); current assessments (the time period of their action is within one year); prospective assessments (for a period of up to five years); strategic assessments (for a period of more than five years);

- according to the level of accuracy of estimates, we can distinguish qualitative and quantitative estimates of the effectiveness of technical service systems.

When evaluating the effectiveness of technical service systems, all available information can be divided into: 1) relevant (relevant) and irrelevant (irrelevant) to the problem of evaluating effectiveness [[18], c. 266];

2) according to the location of the information source, information can be classified into internal and external; 
3) by the nature of the information used for assessments, one can distinguish: deterministic information; random variables (data); uncertainty, which can be understood as the possibility of counteraction by a reasonable opponent or the lack of information;

4) the form of information presentation can also be a sign of information classification. The form of providing information affects the methods of information processing used [[18], c. 266]. In the case of a subject form of information presentation, logical methods are used to evaluate the effectiveness of technical service systems. In the presence of quantitative data, it becomes possible to use numerical methods for analyzing and evaluating the effectiveness of these systems;

5) according to the degree of processing, information is divided into primary and secondary information. Primary information includes information that is collected for the first time and that has not been processed before. The category of secondary information includes data that is previously processed information (scientific articles, analytical reports, forecasts, etc.).

Information about the effectiveness of technical service systems can come from external entities: suppliers, consumers, competitors, intermediaries, state statistics bodies, and others. This information is considered external. Internal sources of information are: accounting data; management accounting data, and more.

According to such a classification factor as the goals of evaluating the effectiveness of technical service systems, the following types of assessments can be distinguished: assessment of the volume of the order portfolio; assessment of the break-even of the machine maintenance system; assessment of the level of equipment utilization; assessment of labor productivity; assessment of the level of work safety; assessment of the effectiveness of inventory management of spare parts; assessment of the effectiveness of fixed and working capital management, and others.

Based on the control functions in the machine maintenance system, the following types of assessments can be distinguished:

- evaluation of the effectiveness of setting goals for the operation of the machine maintenance system. Such an assessment consists in checking the correctness of the formation of the goals of the functioning of the technical service systems. This assessment is important because the management believes that in the case of incorrectly set goals, the technical service system cannot work effectively;

- assessment of the correctness of marketing in the technical service. Such an assessment is to check the correctness of the choice of technologies and equipment for the maintenance of machines;

- assessment of the effectiveness of management in the management system of the technical service complex. Such an assessment is to determine the effectiveness of ensuring a balance in the triangle "people-goalsresources" in the process of activity of technical service organizations.

When evaluating the effectiveness of the management of the system of technical service of machines, an assessment of the correctness of: planning (types of service, equipment loading, personnel placement, spare parts supply, etc.); organization of the service system, including personnel selection; effectiveness of personnel motivation systems of service organizations; systems for monitoring the functioning of service organizations; the level of quality of technical service services provided, and so on.

At the macroeconomic level, the following indicators can be evaluated: the share of organizations of technical service of machines in the gross national product, gross domestic product, gross regional product; the share of the national market of technical service services in the structure of the global market of such services; the share of technical service organizations in budget revenues; the contribution of service organizations to the level of employment of the population, and others.

At the mesoeconomical level, the following can be estimated: the share of expenditures of organizations of the national economy on technical services; the labor productivity of employees of technical service systems of machines; the average salary of employees of technical service organizations; the average level of qualification of personnel of technical service organizations, and so on.

At the microeconomic level, the following factors can be evaluated: the machine availability factor; the time between machine failures; the return on capital at such enterprises; the employee productivity; the ratio of spare parts costs to staff remuneration, and so on. 
Methodology for Evaluating the Effectiveness of Machine and Equipment Maintenance Systems

At the level of organizations of technical service of machines in a comprehensive assessment of their effectiveness can be estimated: the number of units serviced in one year of machines; the average cost of one repair; the volume of fixed and/or working capital; labor productivity of employees; return on assets; return on fixed assets, etc.

Such efficiency assessments can be carried out for each type of technical service of machines: planned preventive repairs; restoration repairs; customization (adaptation) of machines to the specific needs of a particular customer; changes in the design of such machines at the request of consumers; modernization of machines aimed at minimizing the moral aging of machines and other areas (for example, work on the disposal of these machines).

When evaluating the effectiveness of machine maintenance systems, an assessment of the level of losses associated with the following aspects can be carried out: an imbalance between planned preventive and restorative repairs at the stage of machine operation; a violation of the complexity in the process of machine maintenance; errors in the schedules for the implementation of the types of technical service provided for by technical regulations; errors in the diagnosis of machines; errors in the technological maps of a certain type of machine maintenance, and others.

The assessment of the quality of services should be recognized as one of the central tasks of complex and thematic assessments of the effectiveness of machine maintenance systems.

The quality of technical service services is a set of properties of this type of technical service service. This particular set of service properties should reflect the ability of this technical service service to meet the specific needs of organizations (machine owners). On this basis, it is possible to characterize the quality of the service of technical service of machines by listing the properties (characteristics) of this service. These characteristics of the technical service service should be reflected in the following documents: technical regulations; service quality standards; technical instructions for performing repair work; other technical documentation for a specific machine (service object).

The development of models of machine maintenance services provides a basis for quantifying the characteristics of such a service. These characteristics should reflect the quality of the technical service provided. In turn, the quantitative assessment of the characteristics of the service can provide an increase in the level of objectivity of assessments of the quality of services. At the same time, it becomes possible to apply service models in the course of their design. Service models can be used to position technical service services in the market. Service models can be useful in developing quality standards for technical service services.

To assess the effectiveness of machine maintenance systems, the use of such types of models can be recommended:

- models of serviced machines of the following types: functional-decomposition representation of serviced machines, aggregate-decomposition representation of serviced machines; representation of serviced machines by the model " characteristic-the tolerance field for this characteristic" ;

- models of the operation stage of machine samples that can be used to calculate the loads and wear of parts. The results of such modeling are useful in forming a program of planned preventive repairs of machines;

- functional-decomposition representation of the machine maintenance system. As functions of such service can be allocated: planned preventive repair; restoration repairs; adaptation of machines to customer requirements; modernization of machines, etc.);

- models of structural elements of the system of technical service of machines (planned preventive, restoration and other types of repairs).

When developing a systematic approach to evaluating the effectiveness of technical service systems for machinery and equipment, the results of previously performed work can be useful [[5], p. 83-104; [6], p. 36-43; [11], p.184-186;[12], p. 228-243; [13], p. 2-5; 14, p. 6].

As part of a systematic approach to assessing the effectiveness of machine maintenance systems, it is recommended to create a table of planned preventive repairs. This can be a table of functions and elements of the system of technical service of agricultural machines [[11], c. 184-186]. In such a table, its rows correspond to the facts during the operation of the machine (for example, 1 year of operation or the number of hours of operation of the machine). The columns of this table reflect the structural elements of the machine (body, engine, other). At the intersection of the rows and columns of such a table, you should write down what technical service operations are performed in relation to the machine elements. An example of such a table is given in Table No. 1. 
Valery Vladimirovich Glushchenko

Table 1: Functional and decomposition representation of the vehicle maintenance system (fragment)

\begin{tabular}{|c|l|c|c|c|c|}
\hline $\begin{array}{c}\text { № } \\
\text { П п }\end{array}$ & $\begin{array}{l}\text { Car elements } \\
\text { /Facts of the car } \\
\text { operation process }\end{array}$ & $\begin{array}{c}\text { Car electrical } \\
\text { system }\end{array}$ & Car engine & Undercarriage & Car interior \\
\hline & $\begin{array}{l}\text { 1 year of vehicle } \\
\text { operation }\end{array}$ & $\begin{array}{c}\text { Replacing light } \\
\text { bulbs }\end{array}$ & Oil change & & $\begin{array}{c}\text { Replacing the } \\
\text { air filter }\end{array}$ \\
\hline & $\begin{array}{l}\text { 2 year of operation of } \\
\text { the car }\end{array}$ & $\begin{array}{c}\text { Replacing light } \\
\text { bulbs }\end{array}$ & $\begin{array}{c}\text { Replacing the } \\
\text { coolant }\end{array}$ & $\begin{array}{c}\text { Replacing the } \\
\text { air filter }\end{array}$ \\
\hline & $\begin{array}{l}\text { 3 year of operation of } \\
\text { the car }\end{array}$ & $\begin{array}{c}\text { Replacing the } \\
\text { battery }\end{array}$ & $\begin{array}{c}\text { Replacing } \\
\text { candles }\end{array}$ & $\begin{array}{c}\text { Replacement of shock } \\
\text { absorbers }\end{array}$ & $\begin{array}{c}\text { Replacing the } \\
\text { air filter }\end{array}$ \\
\hline
\end{tabular}

Source: developed by the author

This kind of functional-decomposition representation (table of planned preventive repairs) of the subsystem of planned preventive maintenance can be considered as a model of such a system of machine maintenance. This model covers the entire assigned service life (the period of operation of the machines). This table allows you to determine the entire composition of the technical service complex of a certain type of machine for the entire assigned service life. Drawing up such a table of planned preventive repairs of machines allows you to estimate at the design stage of the technical service system: the cost of spare parts; the cost of paying for the labor of technical service employees; the total cost of planned preventive repairs of machines for their entire assigned service life of machines.

Based on this table, you can create a second type of models. This can be a network model of machine maintenance. The task of such a model can be called drawing up the order in time (schedule) of planned preventive maintenance of cars. This model takes into account the logical connection of various types of preventive maintenance of machines. This model allows you to set the exact timing of such repairs of machines. The presence of such a model allows you to plan the production of spare parts for machines in different time periods. This model allows you to predict the cost of maintenance costs of machines in different time periods of their operation.

The schedule for the implementation of specific services of planned preventive maintenance of machines makes it possible to reflect the order and logical connection of work on the technical maintenance of machines. This model is made taking into account the factors of operation. Such facts of the operation process can be: the time interval of operation; the amount of work performed, and more. On the basis of such schedules, it is possible to estimate the time intervals for performing certain types of scheduled preventive repairs. This opens up the possibility to: plan the delivery time of spare parts; to estimate the load of equipment of technical service organizations in a certain period of time; to estimate the need for labor of technical service enterprises in different periods of time; to estimate the costs (outflows of money) of owners for technical service of machines in certain periods of time; to estimate the amount of revenue (inflows of money) in the organization performing technical service of machines, etc.

In the process of evaluating the correctness of the assignment of the moments of performing various types of preventive repairs of machines, the level of wear of machine parts in the process of actual operation of machines should be evaluated.

The third element of evaluating the effectiveness of preventive maintenance systems of machines can be called an assessment of the correctness of the subject description of the operations of preventive maintenance of machines. A descriptive model of any of the operations of preventive repair of machines allows you to assess the adequacy of this operation of the degree of wear of machine parts. At the same time, the descriptive model of the maintenance operation can be the basis for: calculating the cost of the maintenance operation of this machine; compiling a list of parts to be replaced during the repair process; make a list of necessary supplies and tools. Therefore, the descriptive model of the technical service operation can be the basis for the formation of a plan for the material and technical support of planned preventive repairs of machines.

The subject description of the machine repair service may include a description of the following actions: delivery of the machine to a stationary repair point; acceptance of the machine by a representative of the technical service organization; cleaning of the machine from dirt and washing the machine; preliminary diagnosis of the cause of the machine failure during operation; disassembly of the machine in accordance with the preliminary diagnosis of the cause of failure; detection of the failed machine part; confirmation of the data of the preliminary diagnosis of the cause of failure; replacement of the failed parts; assembly of the machine after replacement of the failed parts; 
Methodology for Evaluating the Effectiveness of Machine and Equipment Maintenance Systems

adjustment of the machine; preparation for further operation of the repaired machine; inspection of the machine; payment for repairs by the owner of the machine (customer); transfer of the repaired machine to its owner.

The fourth stage of evaluating the effectiveness of the system of technical service of machines can be considered the analysis of the technological map of the service of technical service of machines. Such an assessment allows you to establish the compliance of the technological map of the repair of the machine with the actual condition of this machine. The technological map of machine repair describes the process of machine maintenance during a certain type of repair. The technological map of the repair of the machine is compiled on the basis of the technical documents of the organization that produces these machines.

A set of technological maps for the implementation of machine maintenance services describes the technology for performing all service operations during the operation of the machine.

The fifth stage of the procedure for evaluating the effectiveness of machine maintenance systems should be recognized as an assessment of the quality of these services. Such an assessment of the quality of machine maintenance services can be performed using the service model. This model assumes the description of the service at its four hierarchical levels. At each of these levels, the technical service service is characterized by a certain set of quality indicators. When forming such a model, the three-level service model known in marketing was supplemented with the fourth (strategic and environmental) level [[14], p.6].

The four-level model of the machine repair service consists of such hierarchical levels and structural elements. At the first hierarchical level of this model, there is a description of the basic benefits of the machine recovery service: restoring the machine's operability; ensuring the safety of the machines after an accidental failure in the course of their operation. The second level of the model under consideration characterizes the named service of the restoration technical service in its practical implementation: the period of repair; the depth of repair ( the average share of replaced elements and parts); the cost of repairs; the availability of repair services for a certain type of machine in a given geographical area(region); the inter-repair period (or time to failure), and more. The third level of the machine repair model describes this service "with reinforcement" and includes: the existence of a service for delivering failed machines to the repair base; the possibility of leaving the repair team to the location of the failed machine for its repair at the site of the breakdown; the possibility of carrying out the repair of this type of machine on credit; the duration of the warranty period (period) for the performed repair of machines; the availability of discounts from the cost of repairs when re-contacting this organization of technical service of machines; the possibility of insurance of the results of repairs, etc. The fourth level of the maintenance service model describes the environmental, socio-economic and strategic consequences of high-quality repair of such machines. This level of the model reflects the ability to provide as a result of the restoration repair: the safety of the operation of the machines; the ability to operate the machine; extending the life cycle of machines; reducing the cost of resources and minerals; reducing the likelihood of causing environmental damage to the environment during the operation of machines, etc.

The four-level model of the machine maintenance service is a hierarchically constructed set of indicators. These indicators describe the characteristics and level of quality of the technical service of the machines. The creation and practical use of four-level models of each type of machine maintenance services will increase the validity and reliability of management decisions. Such solutions are important when designing or analyzing the effectiveness of machine maintenance systems. In addition, such models can be useful in comparing and evaluating the quality of technical services provided by different organizations, for different types of machines and other.

\section{DISCUSSION}

When evaluating the effectiveness of machine maintenance systems, it can be recommended to perform an analysis of the correctness of the formation (verification) of a four-level model of machine maintenance services. Such verification can be carried out by: expert assessment of the reliability of the description of the hierarchical structure of the model under consideration; assessment of the correctness of the list of indicators in the model; determination of quantitative values of the quality indicators of the machine maintenance service at all its four levels of its hierarchy.

You can use a four-level machine maintenance service model to improve the quality of these services. In this case, we can recommend using the following algorithm to improve the quality of the technical service: a four-level model of the technical service of machines is formed; for each of the hierarchical levels, a list of characteristics of this service is determined; for each characteristic, a scale is determined for its quantitative assessment; an expert method 
is used to quantify the value of each of the selected characteristics of this service; the assessment of the compliance of the observed level of quality and the desired level of quality of the service is carried out; identify those characteristics of the service that need to be improved; determine the factors that can increase the desired characteristics of the technical service; perform activities that lead to an improvement in the characteristics of the technical service.

In this article, a method of a systematic approach to a comprehensive assessment of the effectiveness of machine maintenance systems is proposed. This technique involves the practical use of a sequence of machine maintenance models. This set of models includes: a table with a list of machine maintenance services; a network schedule of individual machine maintenance services; a set of descriptive models of all machine maintenance services; a set of process maps of machine maintenance services; and four-level models of all machine maintenance services.

In the interests of organizational support for the development of the methodology of system analysis of the effectiveness of service systems, it can be recommended to create departments of scientific support for technical service of mechanical engineering products in technical universities.

The analysis of the possibility of using this technique for various mechanical engineering products was carried out. This analysis showed the possibility of using this technique to evaluate the effectiveness of technical service systems for various categories of mechanical engineering products.

\section{CONCLUSION}

This article develops the methodological provisions of the system approach to evaluating the effectiveness of machine maintenance systems. The article proves that the system of technical service of machines is a complex system. Therefore, the system of technical service of machines has the following properties: a large number of elements; hierarchy; efficiency; versatility; reliability and other properties. The methodology includes the use of several types of technical service models. The practical use of the set of models proposed in the article can improve the accuracy and reliability of evaluating the effectiveness of machine maintenance systems. The article proves that for the further development of the methodology for evaluating the effectiveness of machine maintenance systems, the creation of specialized laboratories and departments in universities can be recommended. These may be departments of theory and technology of technical service of machinery and equipment.

\section{SOURCES OF FUNDING}

This research received no specific grant from any funding agency in the public, commercial, or not-for-profit sectors.

\section{CONFLICT OF INTEREST}

The author have declared that no competing interests exist.

\section{ACKNOWLEDGMENT}

None.

\section{REFERENCES}

[1] Kozarez I. V., Drikoz A. A., Kupreenko O. A., Uralov S. V. System of maintenance and repair of machines, as an element of technical service//Bulletin of the Bryansk State Agricultural Academy. 2019. No. 6 (76). pp. 5558.

[2] Kuznetsov P. N., Khatuntsev V. V., Kuznetsova A. P. Information and technical support of the processes of technical service of equipment//Science and Education. 2019. Vol. 2. no. 2. p. 216.

[3] Vergazova J.G., Antonova U.Yu. Possibilities of joint use of quality management methods at technical service enterprises//Research Result. Business and Service Technologies. 2017. Vol. 3. no. 2. pp. 31-39 
[4] Bedarev I. V., Drozhnevsky A. G., Tikhonovsky V. V. Analysis and assessment of the level of existing technologies of technical service during technical inspection and repair//In the collection: Organization and road safety. materials of the XI International scientific and practical conference: in 2 volumes. 2018. pp. 3639.

[5] Glushchenko V. V. Analysis of technical service systems for high-tech machine building products/ / Kazakhstan Science Journal. 2019. Vol. 2. No. 10 (11). pp. 83-104.

[6] Glushchenko V. V. Typical representations of technical service systems for agricultural machinery and equipment//Problems of mechanical engineering and automation. 2020. No. 1. pp. 36-43.

[7] Kurochkin V. N., Kushcheva E. N., Poluyan N. S. Mathematical modeling of the system for ensuring the reliability of grain processing equipment//Bulletin of the Agroindustrial Complex of Stavropol. 2016. No. 2 (22). pp. 18-23.

[8] Kurochkin V. N., Kushcheva E. N., Poluyan N. S. Investigation of the efficiency of technical service of grain processing equipment by the method of multifactor experiment//Bulletin of Agrarian Science of the Don. 2015. No. 2 (30). pp. 30-41.

[9] Petrov B. N., Babak S. F., Ilyasov B. G., Yusupov I. Yu. On an approach to the analysis of the structures of multiconnected systems.- In the book: Research on the theory of multi-connected systems. - Moscow: Nauka, 1982, p. 3-12.

[10] Glushchenko V. V., Glushchenko I. I. Methodical bases of the analysis of managerial activity [Electronic resource] / / Molodezhny nauchny vestnik. 2018. No. 1(25), pp. 170-195. URL http://www.mnvnauka.ru/2018/01/Glushchenko.pdf (accessed 11.01.2018).

[11] GlushchenkoV.V. 1990 Functional decomposition representation of complex technical systems. News of the USSR Academy of Sciences, Technical Cybernetics 2184.

[12] Glushchenko V. V., Glushchenko I. I. Paradigm of formation of scientific support for the sphere of postindustrial services. [Electron. Journal]. 2017. No. 10 (23). pp. 228-243. Access mode: (accessed 15.10.2017). DOI:10.5281/zenodo.1012389.

[13] Glushchenko V. V., Modeling methods of technical services for transport operation. Journal of Physics: Conference Series, Volume 1118, 012016, p. 2-5; doi:10.1088/1742-6596/1118/1/012016

[14] Glushchenko V. V., Glushchenko I. I. Four levels of goods: management and marketing. - M.: Ruk. dep. in VINITI No. 591-B-97ot.24.02.1997.

[15] Gritsenko G. M. A systematic approach to forecasting the development of the agricultural infrastructure of the rural municipality//In the collection: Society. Economy. Culture: actual problems, practical solutions. Collection of scientific articles of the X International Scientific and Practical Conference. In 2 parts. Barnaul, 2020. pp. 107-113.

[16] Narkevich L. V. Implementation of a systematic approach in the integrated economic analysis of labor and material resources of agricultural enterprises//Collection of scientific papers "Problems of Economics". 2019. No. 2 (29). pp. 157-168.

[17] Palatkin I. V., Chekh K. Yu. Analysis of the institutional basis of strategic plans for the development of the agro-industrial complex of the Penza region//Theoretical and applied aspects of modern science. 2015. No. 8-6. pp. 162-165.

[18] Glushchenko V. V. Glushchenko I. I. Research of management systems: sociological, economic, forecast, planned, experimental studies: Textbook. Manual for universities (Classification of the Ministry of Higher Education). - Zheleznodorozhny, Moscow region, LLC SPC "Krylia", 2004. -416 p. 